\title{
Testing Weak Form of Market Efficiency of DSE Based on Random Walk Hypothesis Model: A Parametric Test Approach
}

\author{
Ahmed Raihan Sadat (Corresponding author) \\ Lecturer, Department of Business Administration in Finance and Banking \\ Bangladesh University of Professionals \\ Academic Building, Room, \#1404, Bangladesh University of Professionals \\ Mirpur Cantonment, Dhaka-1216, Bangladesh \\ Tel: 880-171-1082-635Ｅ-mail: sadat@ bup.edu.bd
}

Md. Emran Hasan

Lecturer, Department of Economics, Bangladesh University of Professionals Academic Building, Room \# 801, Bangladesh University of Professionals Mirpur Cantonment, Dhaka-1216, Bangladesh Tel: $880-151-5244-794$

Received: March 5, 2019

doi:10.5296/ijafr.v9i1.14454
Accepted: March 24, 2019 Published: March 25, 2019

URL: https://doi.org/10.5296/ijafr.v9i1.14454

\begin{abstract}
Stock market is one great indicator of any country's economic condition. Hence, measuring the capital market in different forms has always been a great interest to finance researchers. This paper measures the market efficiency and randomness of Dhaka stock Exchange (DSE) in weak form employing daily observations (return) from two comparatively new ventured indices viz. DS30 and DSEX. Initially, the study tests for normality using Jarque-Bera test of normality and found data series are not normally distributed. Later, some widely used parametric tests were conducted to examine the historic price dependencies or to examine the random walk hypothesis (RWH) of DSE indices. Augmented Dickey-Fuller test (ADF),
\end{abstract}


Autocorrelation function (ACF), and variance ratio test (Lo \& MacKinlay) were used and all of the results suggested DSE to be not efficient in weak form. Meaning, prices of DSE do not follow a random walk.

Keywords: Dhaka Stock Exchange (DSE), Market efficiency (weak form), Random Walk Hypothesis (RWH), Parametric approach, ADF, ACF, Variance ratio test

\section{Introduction}

Capital market reflects a lot about the financial system and overall economic stance of a country. It is known that for economy to run effectively, surplus fund at different ends should meet the deficit ends. Healthy capital market, therefore, is crucial and desired to any country's economic wellbeing. Needless to mention, efficiency in capital market is necessary to denote it as a healthy one. Hence, the topic of market efficiency or EMH (Efficient Market Hypothesis) gets much attention to both practitioners and academicians to evaluate capital market of a country.

Eugene Fama in 1965 first introduced the idea of efficient market hypothesis (EMH). In theory, EMH considers capital market to follow random walk. Meaning, at any point of time capital market reflects all true market information about a company's share. It also indicates prices in capital market follow a random walk, which means, no investors can achieve above average return by employing investment strategies or following historical price movement. Market efficiency can be divided into three situations, i. e., weak form, semi-strong, and strong form of efficient market (Fama, 1965; Fama, 1991). Majority of the previous researches focus only on testing the market for weak form of efficiency. Because, most of the previous researchers found markets to be not efficient in even weak form, hence, no question of testing it for semi-strong or strong. However, for those who found the market to be efficient in weak form should test for semi-strong or strong form of capital market.

Bangladesh is a country where economic activities are at rise. However, the two stock exchanges, Dhaka Stock Exchange (DSE) and Chittagong Stock Exchange (CSE), are yet to achieve the desired growth and stance. This research will investigate the efficiency of DSE only in weak form because of very limited trading value and amount in CSE. Specific research objectives of this paper are:

- To calculate return series for DSE index

- To employ RWH model to test weak form market efficiency of DSE

- To evaluate historical price dependency on current market price

Testing market efficiency in weak form in Bangladesh capital market is not a new avenue to discover. However, the initiation of this study is based on the introduction of two new indices viz. DS30 and DSEX. Almost all of the previous studies have used DSES and/or DGEN indices. Besides, previous studies did not measure all and only parametric approaches using daily data to test randomness in the market. This paper is instigated to investigate if there are any changes in results of while comparing with the previous findings in existing literature due to the inclusion of two new indices of DSE, incorporating different mix of companies traded 
in Dhaka Stock Exchange.

\section{Literature Review}

\subsection{Efficient Market Hypothesis and Random Walk Hypothesis}

Fama (1970) defined an efficient market as one in which "security prices always going to fully reflect the available information". In other words, according to EMH, the market always truly knows best (Fama, 1970). The efficient market hypothesis states that stock price are traded at fair value and do not let traders to use trading strategies or earning above average return by arbitrage. Fama categorized the old information into three types which gave rise to three forms of market efficiencies: weak, semi-strong and strong.

Random walk hypothesis was first initiated by Bachelier and further modified by Osborne. According the models set by Bachelier and Osborne, share market participants do not rely the analysis on past price movement, instead, behave rationally and do fundamental calculation to measure the price of share based on the performance of the company (Bachelier, 1900; Osborne, 1959). In other words, the prices are set randomly (walk randomly) over the periods without any influence of previous price changes.

\subsection{Empirical Study Evidence}

A large number of studies have been conducted in past few decades in regard to the tests of weak form of market efficiency. Almost all of them tested the weak form of efficiency with Random Walk Hypothesis (RWH) model to see the dependency of historical prices. Many researchers have previously studied stock exchanges of Bangladesh based on different methods to test if prices follow a random walk or not. Numerous studies are found to test the same in different stock exchanges around the world. Some of the relevant research experience is discussed here.

Study on DSE was conducted by some researchers taking monthly data series for the period of 1980-2008 (Joarder, Ahmed, Haque, \& Hasanuzzaman, 2014). They have taken a longer period of time to see if DSE is efficient in weak form or not. The study uses unit root test (ADF method) to check if data follow a random walk and the result rejects the hypothesis of randomness. Therefore, they have concluded DSE as not efficient market in weak form. The study also suggests that the Security Exchange Commission (SEC) should be more organized and strict in terms of monitoring the trading. Besides, they have also suggested to modernize the overall process with the current global standard for effective market control. In one research stock markets of 14 Asia-pacific countries (Australia, Hong Kong, India, Indonesia, Japan, Korea, Malaysia, Pakistan, Philippine, Singapore and Thailand) were tested using monthly observations only (Hamid, Suleman, Shah, \& Akash, 2010). The researchers have taken data dated from 2004-2009. They have tested the normality of data using Jarque-Bera statistics test and found it to be normal for 11 countries. To test price dependency, they have used serial correlation (Ljung-Box Q-Statistics test) and found that no countries other than Pakistan follow a random walk in prices. Later, they have also used ADF test to check stationarity in data and found data becomes stationary at level one. Therefore, they concluded data follow a random walk and 14 Asia-pacific countries' market are not efficient in weak 
form.

In 2012, more insightful research was made keeping the market crush of 1996 and 2010 into consideration (Chaity \& Sharmin, 2012). They have divided the period of 1993-2011 in two segments, 1993-2002 and 2002-2011. They have used logarithm to daily data. Initially, they found data to be not normally distributed, hence, the use of logarithm. Later, they have used $\mathrm{ACF}$ and PACF test to see randomness. ARIMA model is implemented in this paper to see the non-randomness of the stock market. Karachi Stock Exchange (KSE) of Pakistan is another emerging stock exchange. A study took place in 2013 conducted by some local researchers (Rabbani, Kamal, \& Salim, 2013). They have applied ADF test and found the existence of unit root in return series. They have concluded that KSE of Pakistan is not efficient in weak form. One of the distinguishable features of this study was again the subdivision of timeline based on the stock market crush of Pakistan.

In Bangladesh, some researches were conducted based only on the CSE keeping DSE aside. One of the researches has used the daily return series of CSE index from the period of 20062015 (Rahman, Simon, \& Hossain, 2016). This research is more of an elaborative one because the research is divided into two segments of tests. Firstly, the researchers have conducted non-parametric tests because, data was found as not normally distributed. Later, parametric tests were also employed to see the nature of the data. All together they have applied unit root test (ADF), ACF, runs test, variance ratio test apart from other descriptive statistics tests. All the conducted test results rejected the null hypothesis of the paper, which means, data series do not follow a random walk. And CSE is not an efficient market. Following the same pattern of using both parametric and non-parametric tests based on daily data of CSE a research took place in 2016 (Hussain, Nath, \& Bhuiyan, 2016). All combined they have used autocorrelation coefficient test, L-B statistics and runs test check market efficiency of CSE. Examining all the factors they have concluded that CSE does not follow a random walk and market is not efficient in weak form.

Notwithstanding, a study based on the daily share price of around 100 listed companies of DSE was examined (Hasan, Kamil, \& Baten, 2011). Although, it found DSE to be not efficient, it observed something interesting. The market inefficiency was increasing over the passage of time. The researchers have concluded observing that by the time more historical data have taken place market participants were able to predict more about the stock price movements, which clearly denies the basic assumptions of RWH model. In 2015, a study was conducted considering the stock exchanges of Hong Kong, Korea, India, Taiwan and Pakistan (Shaheen, Rehman, \& Haq, 2015). The study was based on daily data from the period of 2000-2012. They have applied Jarque-Bera test to measure the nature of data. To test the randomness of data or efficiency in stock market ADF, serial correlation tests were used. Notwithstanding, Korean stock exchange is found to be efficient. All the other studied exchanges were found inefficient. However, in Hong Kong in few lags return series were found to be efficient. A study on DSE took place in 2013 considering the daily data from 2002-2010. This research gives a more in-depth insight about DSE. Researchers have selected twelve randomly picked companies from DSE. Furthermore, they have divided the timeline in three segments, 2002-04, 2005-07, and 2008-10. In this way, the strategy makes 
the study less bias and more robust. They have used both parametric and non-parametric tests such as, autocorrelation test, unit root test, and runs test. They have found data series to be not random in nature. Later, they have applied ARIMA model and found ability to forecast with historical pattern. Therefore, the researchers have concluded by saying DSE prices do not follow a random walk and stock exchange is not efficient. There are many other researchers who have also conducted the study applying parametric and non-parametric testing methods (Khandoker, Siddik, \& Azam, 2011; Ali, 2012; Raquib \& Alom, 2015). In all the cases DSE is found to be not efficient. In other way, the prices do not follow a random walk in Dhaka Stock Exchange.

\subsection{Literature Gap}

This is understandable that the research gap in this area of work is very narrow because of enormous existent literature. But it is to mention that DSE introduced new indices in 2013. The inclusion of new indices has generated the purpose of making this study. This research in one hand includes daily return series data. On the other hand, the study includes the latest indices of DSE, which are DS30 and DSEX. Therefore, the test of randomness and market efficiency with two new indices will add value to the existing literature.

\section{Methodology}

\subsection{About DSE}

DSE is one of the two stock exchanges established and operated in Bangladesh. DSE works as a separate corporate entity under the Companies Act 1994. DSE started the journey back in 1954, however, started the basic operation from 1956 in Narayangonj. Later, it shifted to Dhaka in 1958. DSE operation was closed after the independence of Bangladesh from 1971 till 1976. Currently, DSE is regulated by Articles of Association rules \& regulations and by-laws along with the Securities and Exchange Ordinance-1969, Companies Act-1994 \& Securities \& Exchange Commission Act-1993. Although, DSE do not offer diversified range of financial products as of now, but it has equity, mutual funds, corporate bonds, treasury bonds, and debentures. In total, DSE has 578 listed companies from different sectors such as, bank, cement, ceramic, financial institutions, jute, IT etc.

\subsection{Data Collection, Methodology and Hypothesis Development}

Data type is secondary in nature and collected entirely from DSE website (Dhaka Stock Exchange, 2015). This study follows two of the four indices viz. DS30 and DSEX. Data is collected on daily basis. All the daily closing values were taken for the period of 27/1/2013 to 25/11/2018, almost 5 years. In total the study has 1410 daily observations to run different tests. As the research trying to focus on historical price dependency, return series of DSEX and DS30 is calculated. Following formula is used to calculate the return (RT) for two indices:

$$
\mathrm{RT}_{\mathrm{t}}=\ln \left(\frac{P r_{t}}{P r_{t-1}}\right) * 100
$$

Where, 


\section{MInstitute ${ }^{\text {Mit }}$}

$\operatorname{Pr}_{t}=$ present value of index at time " $\mathrm{t}$ "

$\operatorname{Pr} r_{t-1}=$ index price one period before the current price

After calculating the return series for DSEX and DS30, normality test is conducted. Most common test for normality is Jarque-Bera test of normality. Under Jarque-Bera test of normality, the null hypothesis is stated as the variable is normally distributed while the alternative hypothesis states that the variable is not normally distributed. To test descriptive statistics using the following formula:

$$
\mathrm{JB}=\mathrm{n}\left[\frac{\mathrm{S}^{2}}{6}+\frac{(\mathrm{EK})^{2}}{24}\right]
$$

Where, $\mathrm{S}=$ skewness of data; $\mathrm{EK}=$ Excess kurtosis of the data; $\mathrm{n}=$ sample size

Descriptive statistics will test the following hypothesis:

$\mathrm{H}_{0}$ : Data of return series is randomly or normally distributed

$\mathrm{H}_{1}$ : Data of return series is not randomly or normally distributed

After evaluating the descriptive statistics several parametric tests such as, Unit root (ADF) test, variance ratio test (Lo and MacKinlay), and autocorrelation (ACF) test are employed to test the primary hypothesis of the research. The prime investigation of this research is to test the following hypothesis:

$\mathrm{H}_{0}$ : Prices on the DSE follow a random walk

$\mathrm{H}_{1}$ : Prices on the DSE do not follow a random walk

\subsection{Unit Root Test $(A D F)$}

To check market efficiency, the first and most important step is always to check if stock market return series follow a random walk (Ozdemir, 2008). Unit root test has always been a preferable option for researchers all around the world to test the RWH model on time series data. This paper uses unit root test to check if return series has a pattern or trend. If found, the return series has a constant mean, variance, and covariance; in other words, there is no unit root, hence, data is stationary. If data has unit root, it means, investors cannot predict future by employing trading strategies. To test the unit root, ADF is one of the widely used options. Augmented Dickey-Fuller test (1979) or ADF test is used to see the presence of stationary properties in data series. The null hypotheses of all tests concerning stationarity are stated as the return series is non-stationary.

$\mathrm{H}_{0}$ : There is a unit root in the series (non-stationary)

$\mathrm{H}_{1}$ : There is not any unit root in the series (stationary).

The true model of ADF is assumed to be:

$$
\begin{gathered}
\Delta p_{t}=\alpha_{1}+\alpha_{2} \mathrm{t}+\beta P_{t-1}+\delta \sum_{i=1}^{k} P_{t-1}+\varepsilon_{t} \\
\Delta p_{t}=\alpha_{1}+\beta P_{t-1}+\delta \sum_{i=1}^{k} P_{t-1}+\varepsilon_{t}
\end{gathered}
$$




$$
\Delta p_{t}=\beta P_{t-1}+\delta \sum_{i=1}^{k} P_{t-1}+\varepsilon_{t}
$$

Here three equations can be observed. The first one considers a constant term, denoted as $\alpha_{1}$, and a trend term $\alpha_{2}$. Second equation incorporates only the constant term. Finally, the third equation does not include intercept and trend term.

\subsection{Autocorrelation (ACF)}

Autocorrelation function test or ACF test is used to see the randomness in data series. It measures the degree of correlation between the current stock returns and lagged observations or degree of independence. We test if the correlation in between prices is significantly different from zero. In other words, results close to plus or minus one refer to strong correlation between return series.

$$
\rho_{k}=\sum_{t=1}^{n-k}\left(R T_{t}-\overline{R T}\right)\left(R T_{t+k}-\overline{R T}\right) / \sum_{t=1}^{n}\left(R T_{i}-\overline{R T}\right)^{2}
$$

Here, K means lag numbers. RT means real rate of return.

The autocorrelation test measures the level of serial correlation coefficient. Alternative hypothesis, DSE is not efficient in weak form level, is accepted when findings suggest that return series of stock prices are correlated.

\subsection{Variance Ratio Test}

Variance ratio test is used particularly in situations where the return series of stock prices are not normally distributed. To test the predictability of share prices Lo and Mackilay (1988, 1989) have developed a test, overlapping variance ratio test, which examines the return series by comparing the variances among the data. Meaning, it wants to determine whether previous data has influence over the current and coming share prices. Variance ratio test can calculate both homoskedastic and heteroskedastic random walks, using the asymptotic normal distribution. Following hypothesis will be tested in variance ratio test:

$\mathrm{H}_{0}$ : Return series follows a random walk [VR $(q)-1=0$ ]

$\mathrm{H}_{1}$ : Return series does not follow a random walk [VR $(q)-1=0$ ]

\section{Results}

\subsection{Data Pattern}

Analysis presented in Figures 1 and 2 shows that both the variables - return_DS30 (return series of DS30 index) and return_DSEX (return series of DSEX index) do not follow any specific trend namely upward or downward trend; rather these variables follow random pattern. 


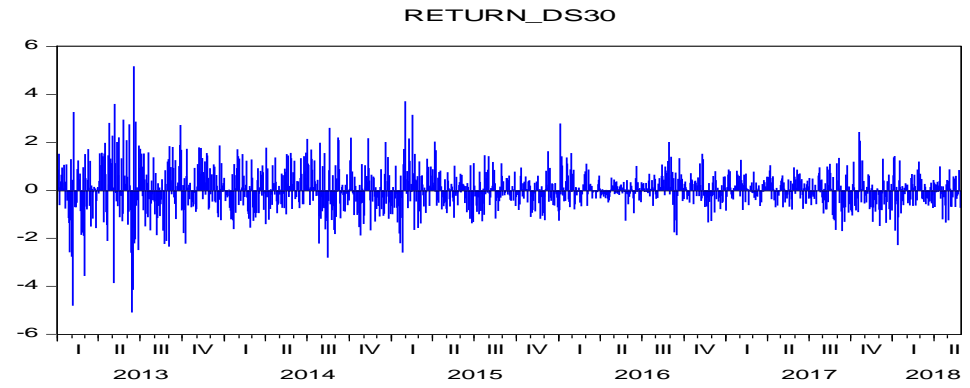

Figure 1. Trend of return on DS30

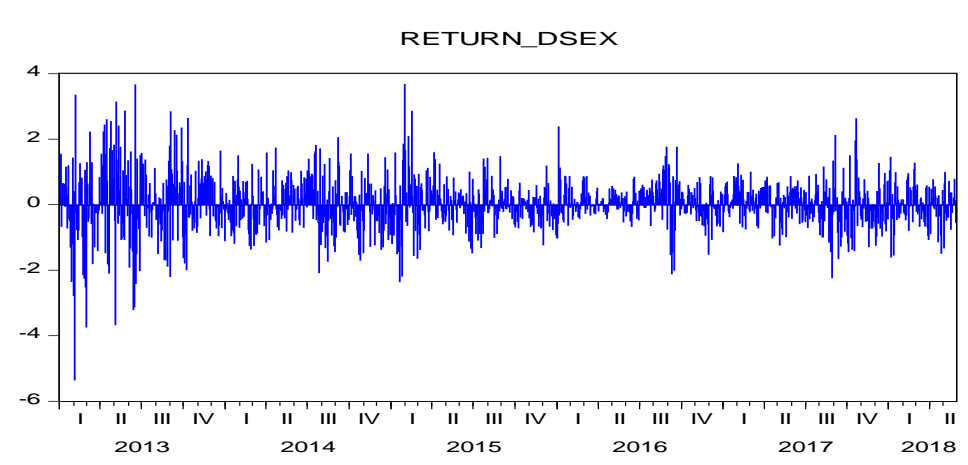

Figure 2. Trend of return on DSEX

\subsection{Descriptive Statistics - Jarque-Bera Test of Normality}

Normality test - one of the variables diagnostic tests, is performed with a view to checking whether the variables are normally distributed or not. Normality test reveals that both variables are not normally distributed since p-values are very low for Jarque-Bera test statistic (Figures 3 and 4).
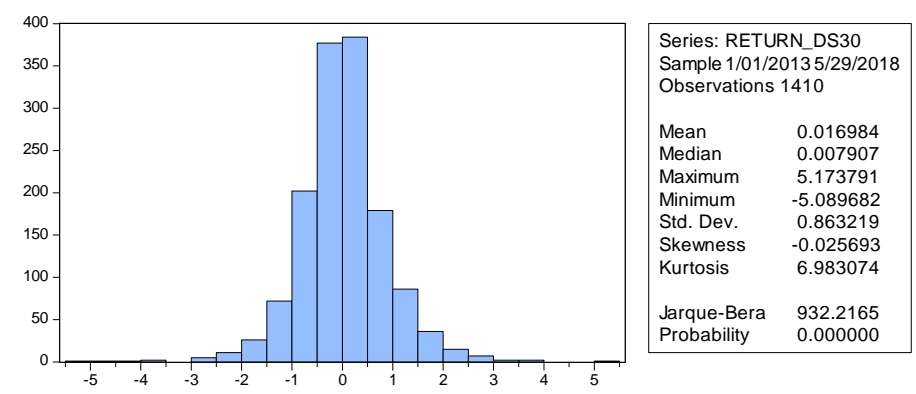

Figure 3. Normality test for return_DS30

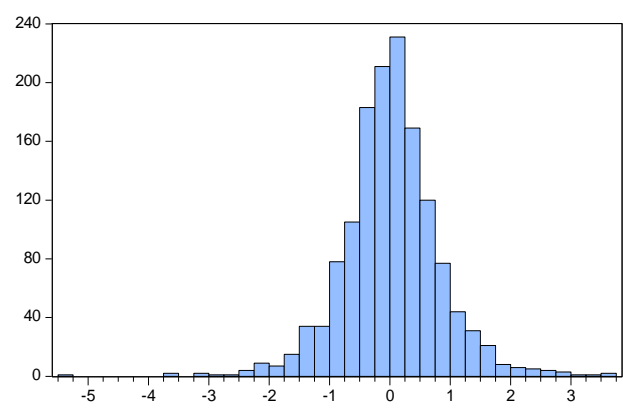

$$
\begin{aligned}
& \text { Series: RETURN_DSEX } \\
& \text { Sample 1/01/20135/29/2018 } \\
& \text { Observations } 141
\end{aligned}
$$

Figure 4. Normality test for return_DSEX 


\section{Mll Macrothink}

International Journal of Accounting and Financial Reporting

ISSN 2162-3082

2019, Vol. 9, No. 1

Mean value for return_DS30 is 0.016984 while it is 0.018655 for return_DSEX (Table 1). Comparing between these two variables in terms of standard deviation, return_DS30 has higher standard deviation than that of return_DSEX. Moreover, both the variables are negatively skewed and leptokurtic as evident by the results provided in Table 1 .

Table 1. Descriptive statistics for return_DS30 and return_DSEX

\begin{tabular}{lll}
\hline Particulars & RETURN_DS30 & RETURN_DSEX \\
\hline Mean & 0.016984 & 0.018655 \\
\hline Median & 0.007907 & 0.013826 \\
\hline Maximum & 5.173791 & 3.684720 \\
\hline Minimum & -5.089682 & -5.358362 \\
\hline Std.Dev. & 0.863219 & 0.813911 \\
\hline Skewness & -0.025693 & -0.102923 \\
\hline Kurtosis & 6.983074 & 6.448186 \\
\hline Jarque-BeraValue & $\mathbf{9 3 2 . 2 1 6 5}$ & $\mathbf{7 0 1 . 0 2 6 2}$ \\
\hline Probability & $\mathbf{0 . 0 0 0 0 0 0}$ & $\mathbf{0 . 0 0 0 0 0 0}$ \\
\hline Observations & 1410 & 1410 \\
\hline
\end{tabular}

Source and note: Authors' calculation. Variables are in log form.

\subsection{Test for Stationarity - Augmented Dickey-Fuller (ADF) Test}

First of all, it must be checked whether the variables of interest are stationary or not with a view to concluding the fact that variables follow random walk path. Previously stated, Augmented Dickey-Fuller (ADF) test is most widely used test in this regard to examine the stationarity. From the results obtained, it can be concluded that both the variables are stationary at level form since the respective p-values are less than 0.05 (Table 2). As a result, the variables - return_DS30 and return_DSEX do not follow random walk. 


\section{Il Macrothink}

International Journal of Accounting and Financial Reporting

ISSN 2162-3082 2019, Vol. 9, No. 1

Table 2. Unit root test

\begin{tabular}{lll}
\hline Variable & ADF test statistic & p-value \\
\hline Return_DS30 & -13.91420 & 0.0000 \\
\hline Return_DSEX & -10.67042 & 0.0000 \\
\hline
\end{tabular}

Source: Authors' calculation.

\subsection{Autocorrelation Function (ACF) and Correlogram}

Stationarity of the variables can be examined by autocorrelation function - ACF (Hall, 1986). The sample autocorrelation function is defined for any lag $\mathrm{k}$ as the ratio of the auto covariance at lag $\mathrm{k}$ to variance. The graphical representation of autocorrelation function is known as correlogram. For non-stationary variables, correlogram shows monotonically decaying pattern or constant trend while it shows random pattern after an abrupt damp down for stationary variables. In this paper, the variables - return_DS30 and return_DSEX are stationary since the correlogram represents random pattern for different lags (Figures 5 and $6)$.

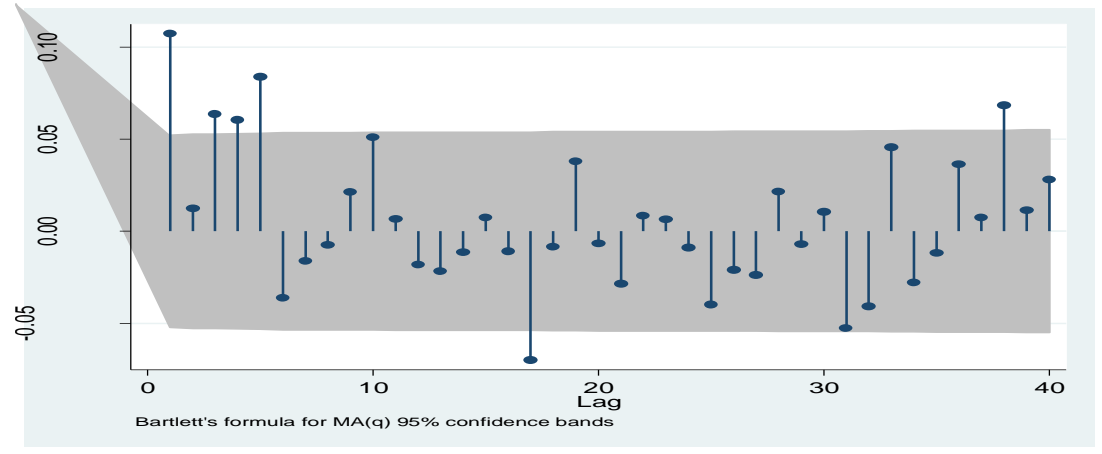

Figure 5. Correlogram for return_DS30

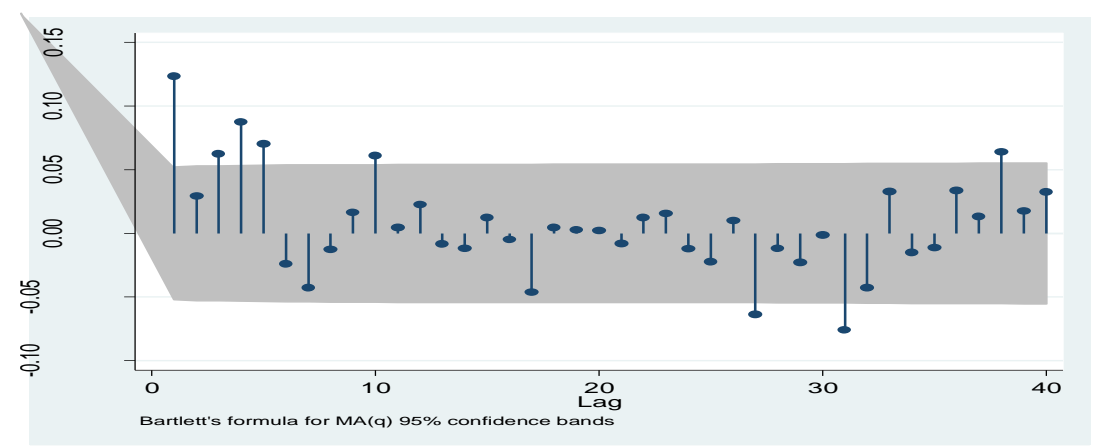

Figure 6. Correlogram for return_DSEX 


\subsection{Variance Ratio Test - Lo \& MacKinlay}

Return series of both indices, DS30 and DSEX, are used to estimate both joint and individual variance ratio test statistics for different lags $(2,4,8$, and 16). The paper includes test for homoskedastic random walks, using the asymptotic normal distribution (Lo \& MacKinlay, 1988).

Table 3. Variance ratio test - result summary

\begin{tabular}{lllll}
\hline \multirow{2}{*}{$\begin{array}{l}\text { Lo and } \\
(1988)\end{array}$} & \multicolumn{4}{l}{ Mackinlay } \\
\cline { 2 - 5 } & DS30 & DSEX & \\
\cline { 2 - 5 } & Z value & P value & Z value & P value \\
\hline Joint $(\operatorname{lag} 2,4,8,16)$ & 16.76809 & 0.0000 & 16.74624 & 0.0000 \\
\hline Lag 2 & -16.76809 & 0.0000 & -16.74624 & 0.0000 \\
\hline Lag 4 & -14.77223 & 0.0000 & -14.82892 & 0.0000 \\
\hline Lag 8 & -10.88637 & 0.0000 & -10.84244 & 0.0000 \\
\hline Lag 16 & -7.914281 & 0.0000 & -7.906906 & 0.0000 \\
\hline
\end{tabular}

Source: Authors' calculation.

In all the test output the significance value is less than 0.05 , therefore, we reject the null and accept alternative hypothesis, which is, return series of indices DS30 and DSEX do not follow random walk. The results remain consistent for both joint test and individual lags for 2 , 4,8 , and 16.

\section{Summary of Findings}

Both the indices, DS30 and DSEX, do not follow any specific pattern. Descriptive statistics results exhibit that DS30 has higher standard deviation compared to DSEX. Normality of the data has been tested using Jarque-Bera test of normality. According to the test results both the index return series, DS30 and DSEX, are found not normally distributed. Hence, we can reject the null hypothesis, that is, data series is not normally distributed. The main motive of this paper is to test the primary hypothesis, which is whether DS30 and DSEX follow a random walk or not. For this reason, both stationarity and randomness of the return series of both indices are examined. Initially, stationarity check is made by using two techniques viz. $\mathrm{ADF}$ and ACF. According the results of ADF, both the return series are stationary, which suggest non-randomness in data. Furthermore, ACF test suggests, shown by correlogram, DS30 and DSEX are stationary. This paper includes Variance ratio test because it is preferable when data series are not normally distributed. According to the variance ratio test results, both the indices do not follow a random walk. Investors can predict the stock prices using trading strategies. Therefore, it can be said that null hypothesis of the research paper is rejected. 


\section{Conclusion}

To conclude, it can be said that according to the results found from both the DSE indices, DS30 and DSEX, DSE is not efficient in weak form, which is supported by most of the previous researches using previous indices and time periods (Ali, 2012; Hasan, 2015). Meaning that, the market participants are influenced by the historical price of shares (existence of historical price dependency). While investing in particular shares, participants rely much on past or historical movement of prices. Investors can employ different forecasting techniques such as ARIMA or such kind of models to predict the future price of stocks (Chaity \& Sharmin, 2012), which in one hand will let them earn above average return. On the other hand, market will be more inefficient. In other words, stock price today does not reflect the exact performance of the share of a company. Without any doubt, this is a bad indicator for the entire economy because, market inefficiency sooner or later leads to market bubble and eventually market crush.

Government and authoritative entities operating and regulating the stock market in Bangladesh have employed some initiatives to reduce market crashes (Ovi, 2018). However, according to the findings of the study, market is yet to receive desired efficiency, hence, indicate unfruitfulness or misalignment of the measures taken. Although, the gap initially found in existing literature is fulfilled to some extent, however, further studies with larger time scale and volume of daily, weekly, and monthly data would enhance the findings of this paper, when appropriate.

Therefore, the suggestion would be for the government and regulatory body now to induce more investment literacy programs for general investors, which was also suggested by (Joarder, Ahmed, Haque, \& Hasanuzzaman, 2014). So that, they don't rely on past movements of stock prices and rumors, rather, perceive investments based on new and market generated factual information resulting from company performance and fundamental calculation. In one side, it will prevent market crushes from happening. On the other side, it will stabilize the market by preventing few investors earning hyper growing return from investments.

\section{References}

Ahmed, M. F., \& Ali, M. B. (2013). Efficiency in Bangladesh Stock Market Behavior: Empirical Evidence. Journal of Business Studies, XXXIV(3), 79-103.

Ali, M. B. (2012). Comparative Efficiency in Emerging Stock Markets: The Case of Dhaka Stock Exchange (DSE) and Chittagong Stock Exchange (CSE). International Journal of Academic Research in Economics and Management Sciences, 1(6), 273-254.

Bachelier, L. (1900). The Random Character of Stock Market Prices. Theorie de la Speculation, 17-78.

Ball, R. (2009). The global financial crisis and the efficient market hypothesis: What have we learned?. Journal of Applied Corporate Finance, 21(4), 8-16.

Beja, A. (1977). The limits of price information in market processes. Berkeley: University of California. 


\section{$\triangle 1$ Macrothink}

International Journal of Accounting and Financial Reporting

ISSN 2162-3082

Chaity, N., \& Sharmin, S. (2012). Efficiency Measures of Capital Market: A Case of Dhaka Stock Exchange. International Journal of Business and Management, 7(1), 102-108.

Chow, K., \& Denning, K. (1993). A Simple Multiple Variance Ratio Test. Journal of Econometrics, 58, 385-401.

Dhaka Stock Exchange. (2015, April 12). Dhaka Stock Exchange Ltd. Retrieved November 25, 2018, from https://www.dsebd.org/recent_market_information.php

Fama, E. (1965). Random Walks in Stock Market Prices. Financial Analysts Journal, 51(1), $75-80$.

Fama, E. (1970). Efficient capital markets: A review of theory and empirical work. Journal of Finance, 25(2), 383-417.

Fama, E. (1991). Efficient Capital Markets. The Journal of Finance, 46(5), 1575-1617.

Grossman, S. J., \& Stiglitz, J. E. (1980). On the impossibility of informationally efficient markets. The American Economic Review, 70(3), 393-408.

Guerrien, B., \& Gun, O. (2011). Efficient Market Hypothesis: What are we talking about?. Real-World Economics Review, 56, 19-30.

Hamid, K., Suleman, M. T., Shah, S. Z., \& Akash, R. S. (2010). Testing the Weak form of Efficient Market Hypothesis: Empirical Evidence from Asia-Pacific Markets. International Research Journal of Finance and Economics, 58, 122-132.

Hasan, M. A. (2015). Testing Weak-Form Market Efficiency of Dhaka Stock Exchange. Global Disclosure of Economics and Business, 4(2), 79-90.

Hasan, M., Kamil, A., \& Baten, A. (2011). Measuring Dhaka stock exchange market efficiency: A stochastic frontier analysis. African Journal of Business Management, 5(22), 8891-8901.

Hussain, S., Nath, S. D., \& Bhuiyan, M. A. (2016). Weak Form Efficiency of the Chittagong Stock Exchange: An Empirical Analysis (2006-2016). International Journal of Business and Social Research, 6(11), 58-66.

Joarder, M. A., Ahmed, M., Haque, T., \& Hasanuzzaman, S. (2014). An empirical testing of informational efficiency in Bangladesh capital market: Informational efficiency in Bangladesh capital market. Economic Change and Restructuring, 47, 63-87.

Khan, M., \& Huq, U. (2013). An Empirical Test of Weak Form Market Efficiency on an Emerging Market: Evidence from Dhaka Stock Exchange. Journal of Business Studies, 34(2), 187-215.

Khandoker, M., Siddik, M., \& Azam, M. (2011). Tests of Weak-form Market Efficiency of Dhaka Stock Exchange: Evidence from Bank Sector of Bangladesh. Interdisciplinary Journal of Research in Business, 1(9), 47-60.

Lo, A. W., \& MacKinlay, A. C. (1988). Stock Market Prices do not Follow Random Walks: Evidence from a Simple Specification Test. The Review of Financial Studies, 1(1), 41-66. 


\section{MlMacrothink}

International Journal of Accounting and Financial Reporting

ISSN 2162-3082

2019, Vol. 9, No. 1

Nwachukwu, J., \& Shitta, O. (2015). Testing the weak-form efficiency of stock markets: A comparative study of emerging and industrialised economies. International Journal of Emerging Markets, 10(3), 409-426.

Nwosa, P., \& Oseni, I. (2012). Efficient Market Hypothesis and Nigerian Stock Market. Research Journal of Finance and Accounting, 2(12), 38-46.

Osborne, M. (1959). Brownian motion in the Stock Market. Operations Research, 145-173.

Ovi, I. H. (2018, February 5). Don't put all eggs in one basket. Retrieved from https://www.dhakatribune.com/business/2018/02/05/dont-put-eggs-one-basket

Ozdemir, Z. (2008). Efficient Market Hypothesis: evidence from a Small Open-Economy. Applied Economics, 40(5), 633-641.

Rabbani, S., Kamal, N., \& Salim, M. (2013). Testing the Weak-Form Efficiency of the Stock Market: Pakistan as an Emerging Economy. Journal of Basic and Applied Scientific Research, 3(4), 136-142.

Rahman, M. S., Simon, H., \& Hossain, M. M. (2016). An Empirical Analysis of Weak Form Market Efficiency: Evidence from Chittagong Stock Exchange (CSE) of Bangladesh. Journal of Statistics Applications \& Probability, 5(3), 535-542.

Raquib, M., \& Alom, K. (2015). Are the Emerging Capital Markets Weak Form Efficient? Evidence from the Model of the Dhaka Stock Exchange. Universal Journal of Accounting and Finance, 3(1), 1-8.

Sewell, M. V. (2012). The Efficient Market Hypothesis: Empirical Evidence. International Journal of Statistics and Probability, 1(2), 164.

Shaheen, F., Rehman, A., \& Haq, M. (2015). Testing the Weak Form of Efficiency of the Asian Emerging Stock Markets. PUTAJ - Humanities and Social Sciences, 22(2), 123-130.

Singh, P., Deepak, C., \& Kumar, A. (2015). Revisiting Weak Form Efficiency of Major Equity Markets in light of Global Financial Crisis: A Panel Data Approach. Asia-Pacific Finance and Accounting Review, 3(1), 17-44.

Tirole, J. (1982). On the possibility of speculation under rational expectations. Econometrica: Journal of the Econometric Society, 50(5), 1163-1182.

\section{Copyright Disclaimer}

Copyright for this article is retained by the author(s), with first publication rights granted to the journal.

This is an open-access article distributed under the terms and conditions of the Creative Commons Attribution license (http://creativecommons.org/licenses/by/4.0/) 